Original Articles

\title{
The norm of assertion: Empirical data
}

\author{
Markus Kneer \\ University of Zurich, Rämistrasse 66, 8001 Zurich, Switzerland
}

\section{A R T I C L E I N F O}

\section{Keywords:}

Assertion

Norm of assertion

Speech acts

Knowledge

Truth

Justification

\begin{abstract}
A B S T R A C T
Assertions are speech acts by means of which we express beliefs. As such they are at the heart of our linguistic and social practices. Recent research has focused extensively on the question whether the speech act of assertion is governed by norms, and if so, under what conditions it is acceptable to make an assertion. Standard theories propose, for instance, that one should only assert that $p$ if one knows that $p$ (the knowledge account), or that one should only assert that $p$ if $p$ is true (the truth account). In a series of four experiments, this question is addressed empirically. Contrary to previous findings, knowledge turns out to be a poor predictor of assertability, and the norm of assertion is not factive either. The studies here presented provide empirical evidence in favour of the view that a speaker is warranted to assert that $p$ only if her belief that $p$ is justified.
\end{abstract}

\section{Norms of assertion}

Linguistic communication occupies a central place in human life, and most human practices heavily rely on it. In uttering a string of meaningful words, we can pursue different goals: Ask a question, give an order, make a request. Most of our utterances, however, are assertions, that is, roughly, utterances by means of which we express beliefs (Williamson, 2002: 74). A question that has received a lot of attention in philosophy of language and linguistics recently regards the conditions under which we are warranted to make assertions.

Inquiries of this sort frequently (though not necessarily) presuppose that (i) assertions of different sorts form a unified type of linguistic move or speech act, and (ii) that 'the speech act [of assertion], like a game and unlike the act of jumping, is constituted by rules.' (Williamson, 1996: 489). Roughly, the presumption is that just as the rules of a particular game constitutively define the game and enable us to play it, the rules of assertion define and sustain the social practice of assertion. What kinds of rules? Four proposals dominate the literature (for recent reviews, cf. e.g. Goldberg, 2015; Pagin, 2016; Weiner, 2007):
Belief: Assert that $p$ only if you believe that $p$. (Bach, 2008; Bach \& Harnish, 1979)

Justified belief: Assert that $p$ only if you justifiedly believe that $p$. (Douven, 2006; Lackey, 2007)

Truth: Assert that $p$ only if $p$ is true. (Weiner, 2005; cf. also Dummett, 1959)

Knowledge: Assert that $p$ only if you know that p. (Adler, 2002; Benton, 2011; Brandom, 1998; DeRose, 1996, 2002; Hawthorne, 2003; Turri, 2011; Williamson, 1996, 2002; for early accounts, cf. Black, 1952; Searle, 1976; Unger, 1975)

The requirements which the above accounts ${ }^{1}$ impose on the speaker differ considerably. Whereas on the last two views, the norm of assertion is factive, on the first two accounts it is acceptable to make an assertion that $p$ even if $p$ is false. Besides the debate regarding which of the above rules is the most promising contender for a norm of assertion, another dispute concerns the appropriate degree of normative force of the rule. ${ }^{2}$ It makes a big difference whether the norm stipulates that one 'must' (Williamson, 2002), 'should' (Douven, 2006; Turri, 2013), 'may' (Turri, 2014) or 'is in a position to' (Dummett, 1959) assert that $p$ only if $p$ is known (or true, or believed with justification). ${ }^{3}$

\footnotetext{
E-mail address: markus.kneer@uzh.ch.

${ }^{1}$ A further, increasingly influential type of account has been proposed by MacFarlane (2011, 2014), according to which assertion is characterized inter alia by a commitment to retract claims that turn out false at a later context of assessment. However, Kneer (2015, in prep.) reports results that challenge its empirical adequacy.

2 This issue dovetails with the controversial distinction between norms of primary propriety (formulated in terms of strict requirements) and secondary propriety (what would be

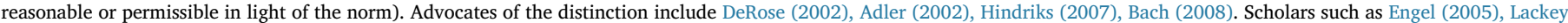
(2007), Kvanvig (2011) reject the distinction.

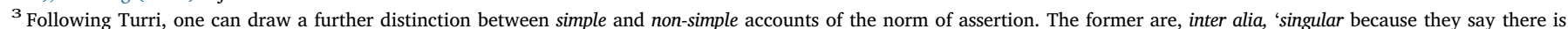

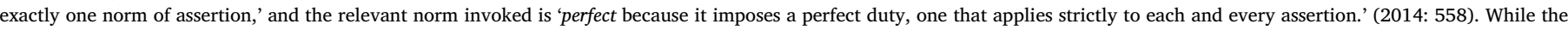

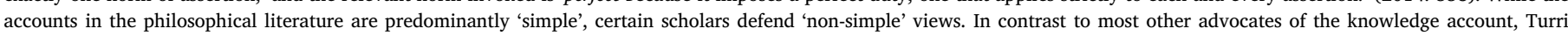

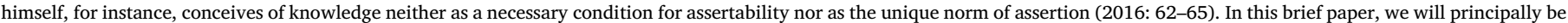
concerned with 'simple' accounts.
} 
Which of the above norms, if any, defines the speech act of assertion is principally a matter of empirical inquiry, an inquiry, that is to say, which 'must face the linguistic data' (Douven, 2006: 450, cf. also Turri, 2013 and Pagin, 2016). Most of the existing evidence to date speaks in favour of the knowledge account, on which there has been increasing convergence over the last decade.

\section{The knowledge account}

A number of ordinary language observations support the knowledge account. An utterance of the sort ' $p$, though I don't know that $p$ ', for instance, sounds infelicitous. Likewise, the fact that the question 'How do you know?' is a standard rejoinder to assertions is considered instructive: It suggests a widely-held presupposition according to which a speaker asserting that $p$ is expected to know that $p$. Perhaps the most persuasive evidence in favour of the knowledge account, however, comes from experiments conducted by John Turri and colleagues. Turri (2013) reports data consistent with the factivity of the norm of assertion (a necessary condition of the knowledge account) and Turri (2015) explores the knowledge criterion directly. In one experiment, participants read a vignette in which the protagonist, Mallory, is asked whether avocados contain vitamin $\mathrm{K}$. In a condition in which Mallory knows, mean agreement with the claim that he should assert that avocados contain vitamin $\mathrm{K}$ is high; when Mallory doesn't know, mean agreement is low. The results are robust across different scenarios and designs. In yet another study (Turri, Friedman, \& Keefner, 2017), knowledge of $p$ proves a better predictor of $p$ 's assertability than belief, truth or certainty of $p$.

The evidence reported by Turri and colleagues suggests that, among the four alternatives surveyed in Section 1, knowledge fares best. However, two important worries persist. First, in all of Turri's experiments the assertability question is framed in terms of whether the protagonist should say that $\mathrm{p}$. But it might be more apt to characterize the norm of assertion in terms of $p$ 's being a permissible, appropriate or, more colloquially, an okay thing to say. The fact that $p$ should be done entails that it is permissible or appropriate to do it, but the reverse relation does not hold. If one should wear a suit to the wedding, it must be permitted or appropriate to do so; if it's permissible to wear jeans it doesn't mean one should. An empirical inquiry into norms of assertion must thus be carefully framed: Which expression is used has important consequences for the normative force at stake, and hence for the type of norm that is supposed to govern assertion. ${ }^{4}$

A second worry regards certain tricky cases that stood epistemology on its head in the early 1960s. Traditionally, knowledge was defined as true, justified belief. However, since the publication of Gettier's 'Is justified true belief knowledge?' (1963), it is widely believed that there are cases that satisfy all three conditions in which we are nonetheless loath to ascribe knowledge. Consider the following example by Goldman (1976): Henry takes his young son for a ride through the countryside and points out objects that come into view. "That's a cow," "That's a tractor," "That's a barn" he says. The scene takes place in broad daylight, the barn is fully in view, Henry has excellent eyesight and he is focused on the task, as there is little traffic. Henry's belief that there's a barn has good evidential support and thus seems well justified, and let's presume it's also true: the object in view is in fact a barn. But unbeknownst to Henry, the area will be used as a film-set the next day. The fields are full of papier-mâché facsimiles of barn façades, which look indistinguishable from real barns from the road. Henry happens to have pointed to the only real barn in the area. Would we call his mental state a state of knowledge? Presumably not. And yet, it seems perfectly acceptable for Henry to assert that the designated object is a barn. Differently put, and as various scholars have suggested, in Gettier cases

\footnotetext{
${ }^{4}$ Turri himself highlights this point (2013: 281) and explicitly encourages experiments with alternative framings.
}

such as the one described, assertability seems warranted despite the fact that the speaker does not have knowledge (Coffman, 2014; Lackey, 2007; Smithies, 2012).

Turri (2016) reports several experiments with Gettier cases which, once again, confirm the knowledge account. Their design, however, is perhaps not ideal. In between-subjects experiments, participants were assigned either an uncontroversial knowledge condition or an accidentally true, yet justified, belief condition. They had to choose among the following four options: The agent (i) knew that $p$ and should assert that $p$, (ii) knew that $p$ and should not assert that $p$, (iii) did not know that $p$ yet should assert that $p$, or (iv) did not know that $p$ and should not assert that $p$. But this bundling of choices is controversial in pragmatic terms. Facing a Gettier vignette, it might seem unpalatable to respond that the agent should say that $p$ though she didn't know that $p$, because there is a strong implicature that the agent was not justified in believing (and hence asserting) that $p .{ }^{5}$ What is more, to decide which account best captures the norm of assertion, it makes good sense to let perceived assertability, knowledge, truth and justification vary independently. The following experiments address the two worries empirically.

\section{Experiment 1}

\subsection{Participants, materials and procedure}

380 participants located in the US were recruited on Amazon Mechanical Turk to complete an online questionnaire. Non-native speakers, subjects failing an attention test and those responding in under 10 seconds were excluded. 337 participants remained (150 female, age $M=36$ years, $S D=12$ years).

The vignette was based on Russell's (1948/2013) Clock Case, an early precursor to Gettier's (1963) examples. It came in three conditions: an uncontroversial case of knowledge (K), a case of justified, yet accidentally true belief (TJB) and a case of false belief (FB). The three scenarios were identical except for the final sentences (the letters in bold were omitted in the vignettes):

June is at the station, talking to her friend Joe on the phone. At some stage, Joe asks her what time it is, since he wants to go for a run before it gets dark. June looks at the platform clock, which says it's $5.30 \mathrm{~h}$. So she concludes it's $5.30 \mathrm{~h}$.

$\mathbf{K}$ The clock shows the correct time, since it has just been controlled that very morning.

TJB Unbeknownst to June, the clock does not work. It has shown the same time for weeks. However, it so happens that it is in fact exactly $5.30 \mathrm{~h}$ when Joe asks for the time.

FB Unbeknownst to June, the clock does not work. It has shown the same time for weeks. The actual time is $4.18 \mathrm{~h}$.

Participants were asked forced-choice yes/no questions about whether they consider $p$ assertable, whether $p$ is true, and whether June knows that $p$ (in that order), where $p$ stands for 'it is $5.30 \mathrm{~h}$ '. The assertability question came in three versions, asking whether participants thought June 'should say' that $p$, that June 'is permitted to say' that $p$ and whether it is 'appropriate for June to say' that $p$ (see Appendix for details). There were thus nine conditions in total ( 3 scenarios $\times 3$ formulations). Each participant was randomly assigned to one of them.

\subsection{Results}

\subsubsection{Assertability results across formulations}

Fig. 1 shows the results for the assertability question across formulations and scenarios. While the impact of formulation on

\footnotetext{
${ }^{5}$ Note that formulating the norm of assertion in terms of what should be said, rather than what it is appropriate or permitted to say, might considerably aggravate the problem.
} 


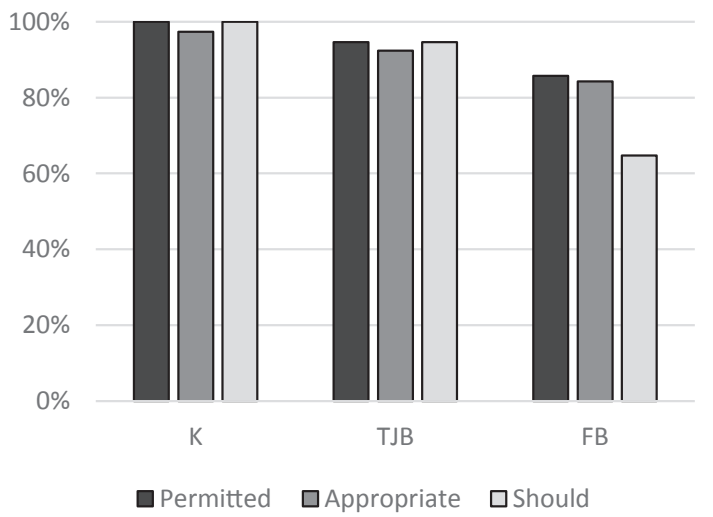

Fig. 1. Judgments of assertability across formulations and scenarios.

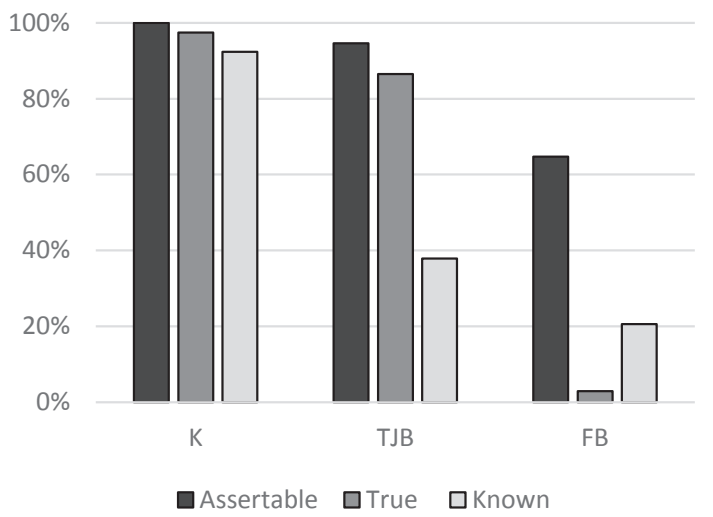

Fig. 2. Judgements of assertability (for the 'should assert that p' formulation), knowledge and truth across scenarios.

assertability was not significant in scenarios $\mathrm{K}\left(\chi^{2}(2)=1.92, p=.384\right.$, $\phi=.132)$ and TJB $\left(\chi^{2}(2)=.23, p=.891, \phi=.045\right)$, it was borderline significant for the FB condition $\left(\chi^{2}(2)=5.39, p=.051, \phi=.228\right)$. The difference is driven by the 'should' formulation, for which assertability ascriptions are significantly lower than for the 'permitted' formulation $\left(\chi^{2}(1)=4.59, p=.032, \phi=.246\right)$ and near-significantly lower than for the 'appropriate' formulation $\left(\chi^{2}(1)=3.64, p=.056, \phi=.225\right)$. Since the assertability results for the 'appropriate' and 'permitted' formulations did not differ significantly $\left(\chi^{2}(1)=.035, p=.851\right.$, $\phi=.021)$, the data-sets were combined to increase power. The main analyses regarding the norm of assertion were thus conducted for assertability in the 'should' formulation on the one hand, and the 'appropriate'/'permitted' formulations on the other.

\subsubsection{General results for 'should'}

The results for assertability (in the 'should' formulation), knowledge and truth are presented in Fig. 2. Knowledge quite clearly doesn't constitute the norm of assertion: While a mere $38 \%$ considered $p$ known in the TJB condition, a significantly higher proportion, 95\%, thought $p$ should be asserted (McNemar test, $p<.001$ ). In the FB condition, only $21 \%$ considered $p$ known, though $65 \%$ thought $p$ should nonetheless be asserted (the difference is significant, McNemar test, $p<.001$ ). ${ }^{6}$ The truth account does little better: Although only $3 \%$ considered $p$ true in the FB condition, $65 \%$ stated that it should be asserted (the difference is significant, McNemar test, $p<.001$ ).

\footnotetext{
${ }^{6}$ Further analyses can be conducted on the basis of the proportions of participants who consider $p$ (i) assertable and known, (ii) assertable and not known, (iii) not assertable though known and (iv) neither assertable nor known; the same holds for the data regarding assertability and truth. The results (see Appendix) are consistent with the ones reported in the main text.
}

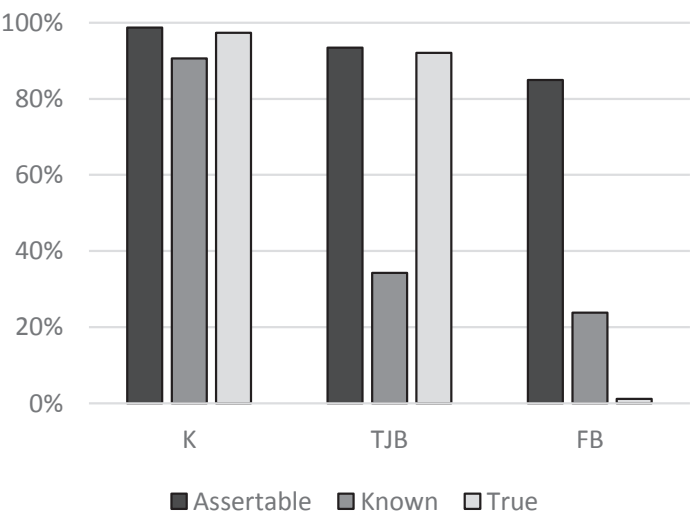

Fig. 3. Judgements of assertability (for the 'appropriate/permitted to assert that $p$ ' formulations), knowledge and truth across scenarios.

\subsubsection{General results for 'appropriate' and 'permitted'}

The results for assertability (in the 'appropriate' and 'permitted' formulations), knowledge and truth are presented in Fig. 3. The knowledge account once again fares poorly: Only 34\% judged $p$ known in the TJB condition, yet a significantly higher proportion, 93\%, considered $p$ assertable (McNemar test, $p<.001$ ). In the FB condition, a mere $24 \%$ judged $p$ known, though $85 \%$ stated that $p$ is assertable (the difference is significant, McNemar test, $p<.001$ ). The norm of assertion isn't factive either: Only $1 \%$ of the participants considered $p$ true in the FB condition, yet $85 \%$ held that it is nonetheless assertable (the difference is significant, McNemar test, $p<.001$ ).

\subsection{Discussion}

Experiment 1 produced two findings: First, judgments of assertability depend on the normative force employed in the assertability question. Responses to the question whether $p$ should be asserted are more sensitive to the truth or falsity of $p$ than responses to the question whether it is appropriate or permitted to assert that $p$. Second, for all three formulations, the ratio of participants who deem $p$ assertable is high under conditions in which the majority withholds the ascription of knowledge (as in the TJB and FB scenarios) or truth (as in the FB scenario). The results are inconsistent with the knowledge and truth accounts of the norm of assertion. Experiment 2 attempts to replicate the findings with a different scenario and controls for a further potential norm of assertion: justified belief.

\section{Experiment 2}

\subsection{Participants, materials and procedure}

403 participants located in the US were recruited on Amazon Mechanical Turk to complete an online questionnaire. Non-native speakers, subjects failing an attention test and those responding in under 10 seconds were excluded. 350 participants remained (151 female, age $M=37$ years, $S D=11$ years).

Participants were randomly assigned to one of three conditions of the well-worn American Car vignette (Nichols, Stich, \& Weinberg, 2003), in which Bob's friend Jill has driven a Buick (an American car) for years. In the knowledge condition K, Jill still drives a Buick. In the Gettier condition TJB, Jill has replaced it with a Pontiac (also an American car), of which Bob is unaware. In the false belief condition FB, Jill now drives - unbeknownst to Bob - a Mercedes (a German car). Bob's wife wants to know what kind of car Jill drives. Participants were asked forced-choice yes/no questions about whether $p$ is assertable, whether Bob really knows that $p$, whether $p$ is true and whether Bob is justified in believing that $p$ (in that order), where $p$ stands for 'Jill drives an American car' (the vignette and questions can be found in the 
Appendix). As in the previous experiment, the formulation of the assertability question varied. Participants were randomly assigned either to the question whether 'Bob should assert that $p$ ' or whether it 'would be appropriate for Bob to assert that $p$ '. (Since the data for 'appropriate' and 'permissible' was near-identical in Experiment 1, only the former formulation was used.)

\subsection{Results and discussion}

Pearson's Chi Square tests for assertability ascription revealed a significant effect of scenario $\left(\chi^{2}(2)=42.73, p<.001, \phi=.349\right)$ and a significant effect of the formulation of the assertability question $\left(\chi^{2}(1)=5.50, p=.019, \phi=.125\right)$, cf. the first two bars for each scenario in Fig. 4. Formulation did not prove significant in scenarios $\mathrm{K}$ $\left(\chi^{2}(1)=2.10, p=.147, \phi=.132\right)$ and TJB $\left(\chi^{2}(1)=.001, p=.969\right.$, $\phi=.004)$. In the FB scenario, by contrast, the ratio of participants who judged it appropriate to assert that $p$ significantly exceeded the ratio of participants who judged that $p$ should be asserted $\left(\chi^{2}(1)=10.46\right.$, $p=.001, \phi=.296)$. The results once again demonstrate that the formulation of the assertability question can make a difference.

Replicating the findings of Experiment 1, the data challenges the knowledge account for both formulations of the assertability question. Consistent with philosophical theorizing about Gettier cases, the majority did not ascribe knowledge in the TJB condition, only $32 \%$ did. However, 97\% considered it nonetheless appropriate to assert $p$ and $100 \%$ thought that $p$ should be asserted. In either formulation, assertability significantly exceeded knowledge ascriptions (McNemar tests, $p$ s $<.001$ ). In the FB condition, a mere $14 \%$ judged $p$ known, though $90 \%$ considered it nonetheless appropriate to assert $p$, and $65 \%$ held that $p$ should be asserted. Assertability again significantly exceeds knowledge ascriptions in either formulation (McNemar tests, ps < $.001)$.

Consistent with the findings of Experiment 1, there's also pressure on the factivity of the norm of assertion. In the FB condition, only $3 \%$ of the participants considered $p$ true, though $90 \%$ judged it appropriate to assert $p$ and $65 \%$ thought $p$ should be asserted. For both formulations, assertability significantly exceeds truth ascriptions (McNemar tests, $p s<.001)$.

Is justification the norm of assertion? The results look encouraging. Justification, just like assertability (on either formulation), significantly exceeded chance in all three scenarios (binomial tests, all ps $<.001$ ). In the 'appropriate' formulation, no difference between assertability and justification could be detected in any of the three scenarios (McNemar tests, all ps > .125). For the 'should' formulation, assertability and justification only differed significantly for the FB scenario (McNemar test, $p<.001$ ).

The core findings of Experiment 1 were replicated: Formulation matters, and both knowledge and truth seem unlikely candidates for the norm of assertion. ${ }^{7}$ Justification, by contrast, seems promising: For the 'appropriate' formulation, no significant difference between assertability and justification could be detected for any condition. In the 'should' formulation, justification exceeds assertability in the FB scenario, but still does considerably better as a predictor than knowledge or truth overall. To get clearer on justification as a potential norm of assertion, a more fine-grained experimental approach might be helpful, to which we turn in the next section.

\section{Experiment 3}

The first two experiments used a forced-choice response mechanism. In order to explore whether the results prove robust across

\footnotetext{
${ }^{7}$ Importantly, there seems to be convergence on these findings: In experiments similar in spirit, Reuter and Broessel (in press) as well as Marsili and Wiegmann (in preparation) obtain results consistent with the ones here reported.
}

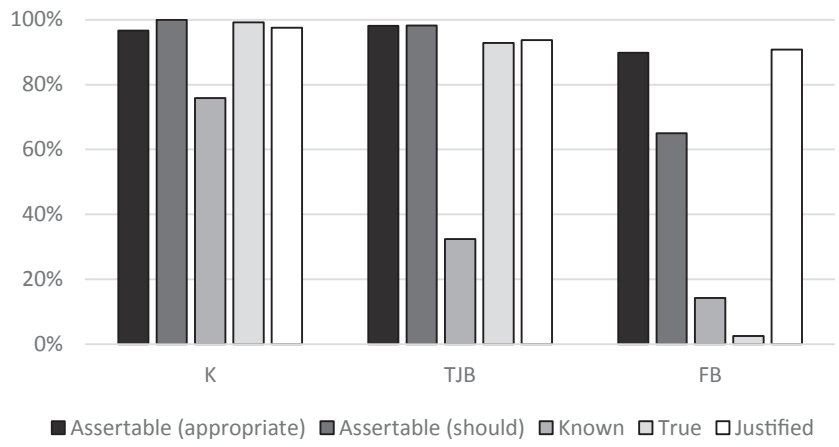

Fig. 4. Proportions of subjects who considered $p$ assertable, known, true and justified across scenarios.

different experimental methodologies, and to run a mediation analysis so as to further explore justification, a Likert scale design was used for Experiment 3.

\subsection{Participants, materials and procedure}

363 participants located in the US were recruited on Amazon Mechanical Turk to complete an online questionnaire. Non-native speakers, subjects failing an attention test and those responding in under 20 seconds were excluded. 297 participants remained (129 female, age $M=36$ years, $S D=12$ years).

The vignette (cf. Appendix) was based on a scenario by Starmans and Friedman (2012): Julie buys yoghurt at the deli. Later that day, her husband asks whether there is yoghurt in the fridge. In the false belief condition FB, Julie has in fact bought sour cream due to inattentiveness; in the knowledge condition $\mathrm{K}$, she has bought yoghurt and her belief appropriately tracks the truth. The Gettier condition came in two variations: (a) Unbeknownst to Julie, her neighbor breaks into her house and replaces her yoghurt with his yoghurt (the 'authentic evidence' case $\mathrm{TJB}^{\mathrm{Aut}}$ ); (b) there was a mix-up at the factory, and the container Julie bought actually contains sour cream. But, unbeknownst to Julie, her neighbor sneaks into her house and replaces her container with another one filled with yoghurt (the 'apparent evidence' case, TJB ${ }^{\mathrm{App}}$ ).

The experiment took a 2 (formulation of assertability question: 'should' v. 'appropriate') x 4 (scenario: $\mathrm{K}$ v. TJB $^{\text {Aut }}$ v. TJB ${ }^{\text {App }}$ v. FB) between-subjects design. Participants were randomly assigned to one of the eight conditions. They were asked to assess the following claims on a 7-point Likert scale ranging from (1) 'completely disagree' to (7) 'completely agree': (ia) 'It is appropriate for Julie to say that $p$ ', or else (ib) 'Julie should say that $p$ ', (ii) 'Julie really knows that $p$ ', (iii) 'It is true that $p$ ' and (iv) 'Julie is justified in believing that $\mathrm{p}$ ', where $p$ stands for 'there is yoghurt in the fridge'. A final question (v) was added, which asked whether 'Julie could be reproached for saying that $p$ ' in order to explore whether a more general standard response to norm-violation reproach - might correlate with assertability.

\subsection{Results and discussion}

\subsubsection{General results}

A 2 (formulation of assertability question: 'should' v. 'appropriate') $\times 4$ (scenario: $\mathrm{K} v$. TJB ${ }^{\text {Aut }} \mathrm{v}$. TJB ${ }^{\mathrm{App}} \mathrm{v}$. FB) ANOVA exploring the impact of formulation and scenario on judgments of assertability revealed a significant main effect of scenario $(F(3,289)=5.31$, $\left.p=.001, \eta_{p}{ }^{2}=.052\right)$, no significant main effect of formulation $(F$ $\left.(1,289)=.188, p=.721, \eta_{p}^{2}=.000\right)$, and no significant interaction $(F$ $\left.(3,289)=2.04, p=.108, \eta_{p}{ }^{2}=.021\right)$. Bonferroni corrected post-hoc tests revealed that assertability in the FB scenario differed significantly from each of the three other scenarios (all $p s<.007$ ). No significant difference in assertability could be detected across the $\mathrm{K}, \mathrm{TJB}^{\mathrm{Aut}}$ and $\mathrm{TJB}^{\mathrm{App}}$ scenarios. For either formulation, mean assertability ratings in 


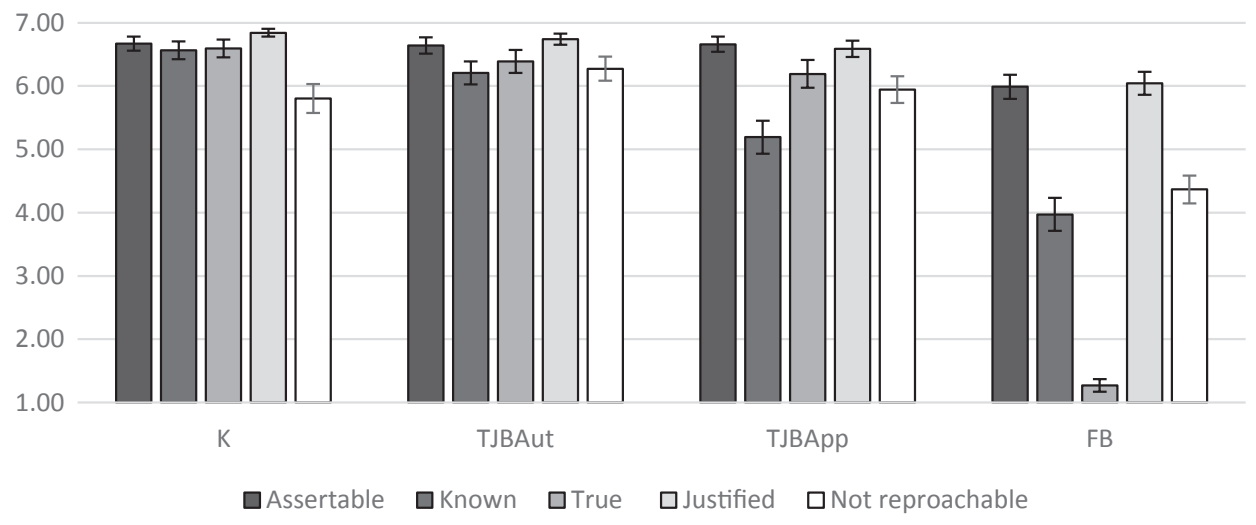

Fig. 5. Mean ratings for assertability, knowledge, truth, justification and absence of reproach across the four scenarios. Error bars denote standard error of the mean.

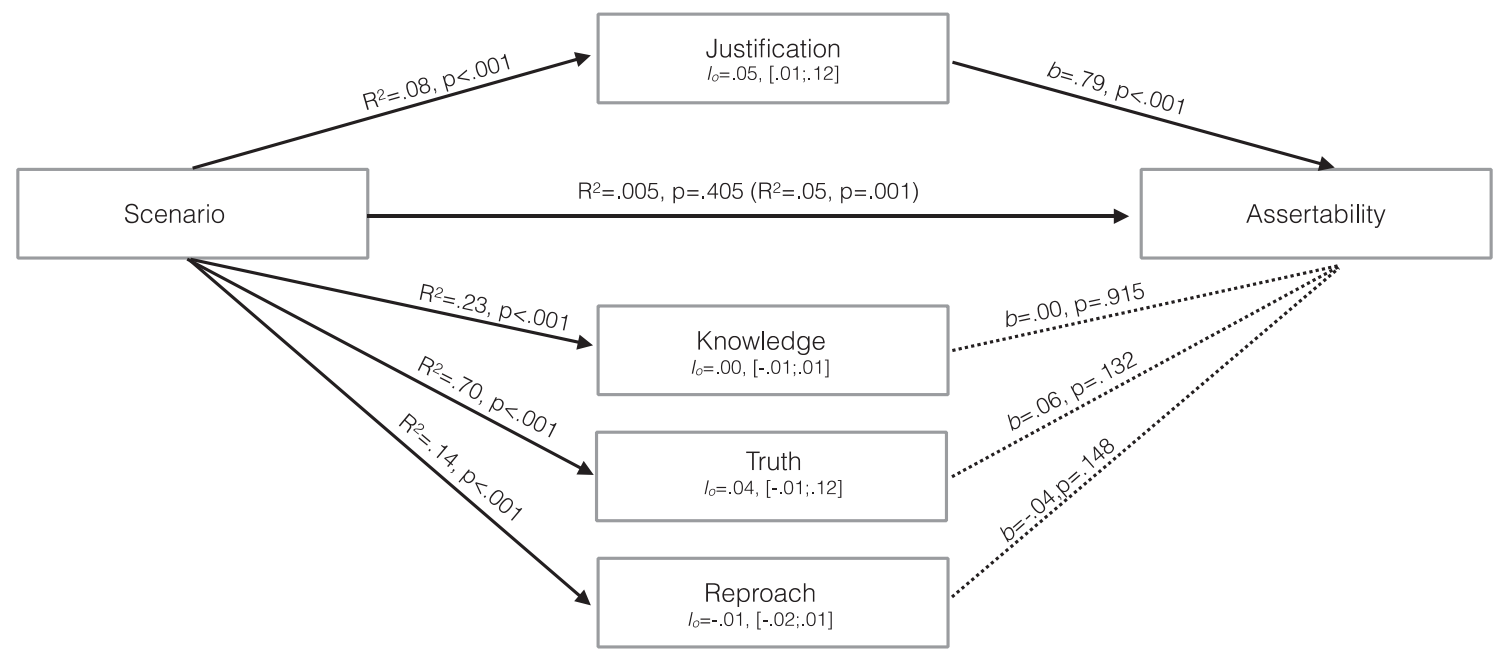

Fig. 6. Multicategorical Mediation Analysis with 5000 bootstrap samples.

all four scenarios significantly exceeded the midpoint (one sample ttests, all $p s<.001$ ), suggesting that assertability is deemed appropriate even in conditions in which the agent does not have knowledge of $p$, and when $p$ is false.

Expectedly, ascription of the potential predictors differed significantly across type (knowledge, truth, justification and absence of reproach), and mean levels of each of the potential predictors differed significantly across scenario (for detailed statistics, see Section 4.1 of the Appendix).

Since no significant difference in assertability ascriptions could be detected across formulation ('should' v. 'appropriate'), the data-sets were combined. The mean levels of ascriptions of assertability and the four potential predictors are graphically represented in Fig. 5. Mean assertability levels significantly exceeded mean knowledge levels in the $\mathrm{TJB}^{\mathrm{Aut}}, \mathrm{TJB}^{\mathrm{App}}$ and the FB scenarios (for the statistics, cf. Tables 5-8 in Section 4.2 of the Appendix), which casts further doubt on the knowledge account. Mean assertability levels also significantly exceeded mean truth levels in the $\mathrm{TJB}^{\mathrm{App}}$ and FB scenarios, challenging the factivity of the norm of assertion. Absence of reproach, too, is a poor predictor, since it differed significantly from assertability in the $\mathrm{K}$ and FB scenarios. By contrast, and supporting the findings from Experiment 2, no significant difference could be detected between the mean levels of assertability and justification for any of the four scenarios.

\subsubsection{Mediation analysis}

A multicategorical multiple mediation analysis with 5000 biascorrected bootstrap samples was conducted using Hayes' PROCESS macro for SPSS (model 4, Hayes, 2017). Given that the fixed factor, scenario, had four levels, three dummy-coded variables were created (cf. Hayes \& Preacher, 2014) with scenario FB as the reference group. ${ }^{8}$ Each dummy-coded variable corresponds to one of the three possible contrasts: $D 1$ explores the contrast for scenarios $\mathrm{TJB}^{\mathrm{App}}$ and $\mathrm{FB}, D 2$ for scenarios $\mathrm{TJB}^{\mathrm{Aut}}$ and $\mathrm{FB}$, and $\mathrm{D} 3$ for scenarios $\mathrm{K}$ and $\mathrm{FB}$.

The results are summarized in Fig. 6. Justification was the only significant mediator, with an indirect omnibus effect of scenario on assertability $I_{o}=.05,[.01 ; .12]$. While an omnibus test for $D 1-D 3$ reveals a significant total effect of scenario on assertability (the $c$ path in brackets), the effect is no longer significant once justification is controlled for as a mediator (the $c^{\prime}$ path). For each potential mediator, the indirect omnibus effects of scenario on assertability $I_{o}$ are stated with $95 \%$ confidence intervals. The indirect individual effects of scenario on assertability through justification were significant for $D 1\left(I_{D 1}=.55\right.$, $[.22 ; .97]), D 2\left(I_{D 2}=.43,[.07 ; .88]\right)$, and $D 3\left(I_{D 3}=.63\right.$, $\left.[.01 ; .12]\right)$. Fig. 6 details the effects of scenario on each of the four potential mediators calculated on the basis of D1-D3 in terms of $R^{2}$. The individual regression coefficients for each of the dummy variables and each of the potential mediators, i.e. the 12 individual $a$ paths, can be found in the Appendix (all $12 a$ paths were significant, all $p s<.003$ ).

Consistent with the findings of Experiments 1 and 2, knowledge and truth once again prove inadequate predictors of assertability, and reproach does little better. The justified belief account, by contrast, holds considerable promise. Our results so far, however, can only establish

\footnotetext{
${ }^{8}$ Nothing hangs on this choice, no matter which scenario is chosen as the reference group, the $a$ paths come out significant for all four potential mediators.
} 
that justified belief is a sufficient condition for assertability. It might still turn out that justified belief is not in fact necessary, and that assertion is governed by an even weaker norm, for instance a norm tied to belief simpliciter. A final experiment was conducted to resolve this remaining question.

\section{Experiment 4}

Experiment 4 focuses on the two weakest norms discussed in the introduction: It explores whether assertability depends on justified belief or belief simpliciter. To do so, a vignette was devised in which the agent asserts that $p$ in the belief that $p$, while its evidential support varies across conditions.

\subsection{Participants, materials and procedure}

162 participants located in the US were recruited on Amazon Mechanical Turk to complete an online questionnaire. Non-native speakers, subjects failing an attention test or a comprehension check were excluded. 149 participants remained (84 female, age $M=35$ years, $S D=10$ years).

The vignette came in two variations, one in which the agent has good evidence for his belief and asserts that $p$, and one in which his evidence for $p$ is poor. The prompt read (variations in square brackets):

Carlos is at the JFK airport in New York, waiting for his flight to Amsterdam. An elderly woman asks him whether he could tell her at which gate the flight to Paris departs. Carlos has a look at the monitor listing the departure gates. [The departure list states that the only flight to Paris leaves at gate 24./He cannot find the flight to Paris in the list. But Carlos has a hunch that it might depart from gate 24, and thus comes to believe that it will.] Carlos says to the elderly woman: "The flight to Paris leaves at gate 24."

Participants were presented with forced-choice yes/no questions about (i) the assertability of Carlos's claim that $p$, (ii) whether his belief that $p$ was justified, and (iii) whether he in fact believed that $p$, where $p$ stands for "the flight to Paris leaves at gate 24" (the order was randomized, cf. Section 5 of the Appendix for the exact formulations). As in the previous experiments, the assertability question came in two versions. One question asked whether Carlos 'should have said' that $p$, the other asked whether 'it was appropriate for Carlos to say' that $p$. There were thus four conditions in total ( 2 types of evidence $\times 2$ formulations of the assertability question); each participant was randomly assigned to one of them. The three target questions were followed by a comprehension question.

\subsection{Results and discussion}

Pearson's Chi Square tests for assertability ascription revealed a significant effect of scenario $\left(\chi^{2}(1)=89.58, p<.001, \phi=.775\right)$, yet no significant effect of the formulation of the assertability question $\left(\chi^{2}(1)=.01, p=.940, \phi=.006\right)$. Since the impact of formulation on assertability responses also proved insignificant for each scenario individually (poor evidence: $\chi^{2}(1)=3.03, p=.082, \phi=.201$; good evidence: $\left.\chi^{2}(1)=2.30, p=.129, \phi=.176\right)$, the datasets were combined for increased power. Fig. 7 graphically represents the proportions of participants who considered $p$ assertable, justified, and who held that Carlos believed that $p$.

In the good evidence scenario, 95\% deemed Carlos's belief that $p$ justified and $93 \%$ considered $p$ assertable (both significantly exceeding chance, binomial tests, $p s<.001$ ). In the poor evidence scenario, $20 \%$ deemed $p$ justified and $16 \%$ considered $p$ assertable (both significantly below chance, binomial tests, $p s<.001)$. For either scenario, the proportions of people who considered $p$ justified and those who considered $p$ assertable did not differ significantly (McNemar tests, $p s>$ .507).

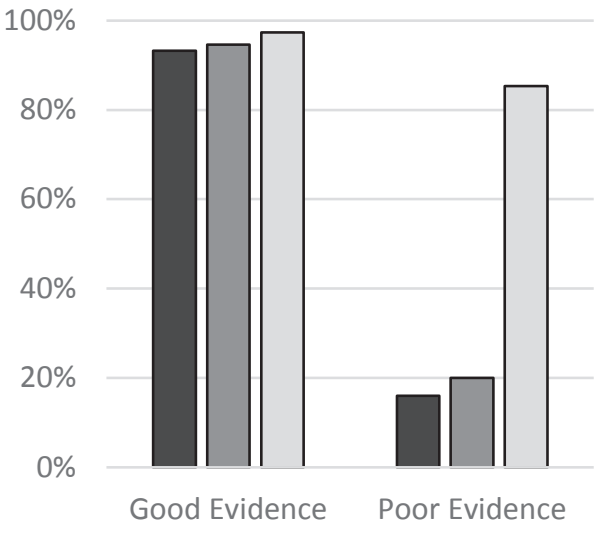

Assertable $\square$ Justified $\square$ Believed

Fig. 7. Proportions of participants who considered $p$ assertable, justified and believed across conditions (good v. poor evidence).

To rule out that the difference in assertability judgments is driven by the perceived absence of belief simpliciter, rather than its justification, participants were also asked whether Carlos in fact believed that $p$. In either scenario, the vast majority did ascribe the belief that $p$ to Carlos (significantly exceeding chance, binomial tests, $p s<.001$ ). Whereas $85 \%$ of the participants responded that Carlos believed that $p$ in the poor evidence condition, only $20 \%$ considered his belief justified (the difference is significant, McNemar test, $p<.001$ ). The low assertability rating in the poor evidence scenario must thus be principally due to the absence of justification, not the absence of brute belief. Differently put, belief, by itself, does not constitute the norm of assertion. Though $85 \%$ of the participants ascribe the belief that $p$ to Carlos, only $16 \%$ consider Carlos's claim that $p$ assertable (the difference is significant, McNemar test, $p<.001$ ).

\section{General discussion}

In a series of four experiments using distinct methodologies and scenarios, we have explored the nature of the norm of assertion, and aspects pertaining to its normative force. As concerns the former, for a speaker to assert that $p$, it is not necessary that she know that $p$, or that $p$ be true. By itself, the belief that $p$, however, provides insufficient warrant to assert that $p$. Instead, the data suggests that a speaker should assert that $p$, or that it is appropriate for her to do so, only when she is justified in believing that $p$. While the negative results are rather conclusive, the positive findings must still be treated with caution: More empirical work is needed to establish whether justified belief constrains assertion across a wide range of contexts, and whether there is indeed but a single norm of assertion.

As concerns normative force: The assertability data of some of the experiments suggests that the framing of the norm of assertion merits further attention. In certain conditions, intuitions as to whether $p$ should be asserted and whether it is permissible or appropriate to do so differ significantly. Future theoretical and experimental work on assertion should explore whether the stringent conception of the norm (invoking what should be asserted, which dominates the empirical literature) is adequate, or whether a more lenient conception of the norm is preferable.

\section{Acknowledgements}

For their insightful comments, I would like to thank Kent Bach, Igor Douven, Manuel García-Carpintero, Margherita Isella, Edouard Machery, Neri Marsili, Peter Pagin, Henrik Singmann, Isidora Stojanovic, Mike Stuart, Johannes Ullrich, Alex Wiegmann and Timothy 
Williamson. I am particularly grateful to Joshua Knobe, John Turri and the Cognition reviewers for very helpful feedback.

\section{Appendix A. Supplementary material}

Supplementary data associated with this article can be found, in the online version, at http://dx.doi.org/10.1016/j.cognition.2018.03.020.

\section{References}

Adler, J. (2002). Belief's own ethics. Cambridge, Mass.: MIT Press.

Bach, K. (2008). Applying pragmatics to epistemology. Philosophical Issues, 18(1), 68-88.

Bach, K., \& Harnish, R. (1979). Linguistic communication and speech acts. Cambridge, Mass.: MIT Press.

Benton, M. A. (2011). Two more for the knowledge account of assertion. Analysis, 71(4), 684-687.

Black, M. (1952). Saying and disbelieving. Analysis, 13(2), 25-33.

Brandom, R. (1998). Making it explicit: Reasoning, representing, and discursive commitment. Cambridge, Mass.: Harvard University Press.

Coffman, E. J. (2014). Lenient accounts of warranted assertability. In C. Littlejohn, \& J. Turri (Eds.). Epistemic norms: New essays on action, belief and assertion (pp. 33-59). Oxford: Oxford University Press.

DeRose, K. (1996). Knowledge, assertion and lotteries. Australasian Journal of Philosophy, 74(4), 568-580.

DeRose, K. (2002). Assertion, knowledge, and context. The Philosophical Review, 111(2), $167-203$.

Douven, I. (2006). Assertion, knowledge, and rational credibility. The Philosophical Review, 449-485.

Dummett, M. (1959). Truth. Proceedings of the Aristotelian Society, 59(1), 141-162.

Engel, P. (2005). Truth and the aim of belief. In D. Gillies (Ed.), Laws and models in science (pp. 77-79). King's College Publications.

Gettier, E. (1963). Is justified true belief knowledge? Analysis, 23(6), 121-123.

Goldberg, S. C. (2015). Recent work on assertion. American Philosophical Quarterly, 52(4), 365-380.

Goldman, A. (1976). Discrimination and perceptual knowledge. The Journal of Philosophy, $73(20), 771-791$.

Hawthorne, J. (2003). Knowledge and lotteriesOxford: Oxford University Press.

Hayes, A. F. (2017). Introduction to mediation, moderation, and conditional process analysis: A regression-based approach. Guilford Publications.

Hayes, A. F., \& Preacher, K. J. (2014). Statistical mediation analysis with a multicategorical independent variable. British Journal of Mathematical and Statistical Psychology, 67(3), 451-470.

Hindriks, F. (2007). The status of the knowledge account of assertion. Linguistics and Philosophy, 30(3), 393-406.

Kneer, M. (2015). Perspective in language. Institut Jean Nicod (ENS/EHESS Paris), Paris.

Kneer, M. (in prep.). Predicates of personal taste: Empirical data.

Kvanvig, J. (2011). Norms of assertion. In J. Brown, \& H. Cappelen (Eds.). Assertion: New philosophical essays (pp. 233-250). Oxford: Oxford University Press.

Lackey, J. (2007). Norms of assertion. Nous, 41(4), 594-626.

MacFarlane, J. (2014). Assessment sensitivity: Relative truth and its applications. Oxford: Oxford University Press.

MacFarlane, J. (2011). What is assertion? In J. Brown, \& H. Cappelen (Eds.). Assertion Oxford: Oxford University Press.

Marsili, N., \& Wiegmann, A. (in preparation). Should I say that?.

Nichols, S., Stich, S., \& Weinberg, J. (2003). Metaskepticism: Meditations in ethno-epistemology. The Skeptics, 227-247.

Pagin, P. (2016). Assertion. In Zalta E.N. (ed.), The Stanford Encyclopedia of Philosophy.

Reuter, K., \& Broessel, P. (in press). No knowledge required. Episteme.

Russell, B. (1948/2013). Human knowledge: Its scope and value. Routledge.

Searle, J. R. (1976). A taxonomy of illocutionary acts. In K. Gunderson (Ed.). Language, mind and knowledge (pp. 344-369). Minneapolis: University of Minnesota Press.

Smithies, D. (2012). The normative role of knowledge. Nous, 46(2), 265-288.

Starmans, C., \& Friedman, O. (2012). The folk conception of knowledge. Cognition, 124(3), 272-283.

Turri, J. (2011). The express knowledge account of assertion. Australasian Journal of Philosophy, 89(1), 37-45.

Turri, J. (2013). The test of truth: An experimental investigation of the norm of assertion. Cognition, 129(2), 279-291.

Turri, J. (2014). Knowledge and suberogatory assertion. Philosophical Studies, 167(3), $557-567$.

Turri, J. (2015). Knowledge and the norm of assertion: A simple test. Synthese, 192(2), $385-392$.

Turri, J. (2016). Knowledge and assertion in "Gettier" cases. Philosophical Psychology, 29(5), 759-775.

Turri, J., Friedman, O., \& Keefner, A. (2017). Knowledge central: A central role for knowledge attributions in social evaluations. The Quarterly Journal of Experimental Psychology, 70(3), 504-515.

Unger, P. (1975). Ignorance: A defense of skepticism. Oxford: Clarendon Press.

Weiner, M. (2005). Must we know what we say? The Philosophical Review, 114(2), $227-251$.

Weiner, M. (2007). Norms of assertion. Philosophy Compass, 2(2), 187-195.

Williamson, T. (1996). Knowing and asserting. The Philosophical Review, 105(4), 489-523.

Williamson, T. (2002). Knowledge and its limits. Oxford: Oxford University Press. 